\title{
The relationship between malaria parasitaemia and availability of healthcare facility in Mpwapwa District, central Tanzania
}

\author{
L.E.G. MBOERA ${ }^{1 *}$, M.L. KAMUGISHA ${ }^{2}$, S.F. RUMISHA ${ }^{1}$, H.A. MSANGENI ${ }^{2}$, \\ V. BARONGO ${ }^{2}$, F. MOLTENI ${ }^{3}$ and A.Y. KITUA ${ }^{1}$, \\ ${ }^{1}$ National Institute for Medical Research, P.O. Box 9653, Dar es Salaam, Tanzania \\ ${ }^{2}$ Tanga Medical Research Centre, Tanga, Tanzania \\ ${ }^{3}$ National Malaria Control Programme, Dar es Salaam, Tanzania
}

\begin{abstract}
A study was carried out in six villages located at different altitudes in Mpwapwa district of central Tanzania to determine malaria parasitaemia and transmission levels in villages with or without health care facilities. A total of 1119 schoolchildren (age = 5.9-12.3 years) were examined for malaria parasitaemia. Plasmodium falciparum was the predominant malaria species accounting for $92.8 \%$ of all species. The average malaria prevalence rate among schoolchildren was $25.8 \%$ (range 1.5-53.8\%). The geometric mean parasite densities for $P$. falciparum was $361(\mathrm{~N}=286)$. Higher malaria prevalence was observed in villages at lower $(<1000 \mathrm{~m})$ than at intermediate $(1000-1500 \mathrm{~m})$ or higher $(>1500 \mathrm{~m})$ altitudes. Schoolchildren in areas with health care facilities were less at risk of acquiring malaria by $33.4 \%$ as compared with those living in areas without health facilities. Mean packed cell volume in schoolchildren was 38.5\% (range $=35.2-41.0 \%$ ). Splenomegaly was observed in $18.1 \%(0-40.2 \%)$ of the schoolchildren examined and it was higher among those in villages without health care facilities. Anopheles gambiae sensu lato was the only malaria vector found in the district and was found in all villages and at all altitudes. Sporozoite rate in An. gambiae s.l. ranged from 0-10.5\%, with the lowland villages recording the highest rates. This study indicates that altitude and geographical accessibility to healthcare service are important determinants of malaria infection among rural communities in Tanzania.
\end{abstract}

Key words: malaria, schoolchildren, altitudes, health care facility, Tanzania

\section{Introduction}

Malaria remains a major public health problem in subSaharan Africa, with approximately 1 million deaths and more than 400 million cases a year. In Tanzania, it is the leading communicable disease problem. Of the total Tanzanian population of 34.5 million, over $95 \%$ is at risk of malaria. The disease is responsible for 33\% of hospital attendance and 54\% of hospital deaths (Ministry of Health, unpubl.). These deaths are only a small proportion of those, which occur at home, unreported.

Several factors have been shown to influence malaria transmission and malaria risk in sub-Saharan Africa. These include intrinsic factors such as the parasite, mosquito or host (Marsh, 1993; Lindsay et al., 2001; Verhoef et al., 2002; Koenraadt, 2003) as well as environmental and climatic conditions (Ondongo-Aginya et al., 2005). Moreover, factors such as human activities (e.g. water and agricultural developments) and knowledge of the disease (Karanja et al., 1999) have been described to closely influence malaria prevalence (Ondongo-Aginya et al., 2005).

It has been established that in any given area, the most exposed households to malaria are those in the more remote part of a village or district. (Billingsely et al., 2006). The reason for such variation has been attributed to heterogeneity in entomological inoculation rates (Charlwood et al., 1995).
Interestingly, in a recent study in Iringa, Tanzania, higher malaria prevalence was observed among children living in villages without healthcare facilities than in those with healthcare facilities (Mboera et al., 2006) indicating that there are still more other factors which influence malaria risk in any given area. This aspect has not been adequately studied. It was therefore, the objective of this study to determine the prevalence of malaria parasitaemia among schoolchildren living in village with or without healthcare facility in rural Mpwapwa in central Tanzania.

\section{Materials and Methods}

\section{Study area}

The study was carried out in Mpwapwa district $\left(6^{\circ} 45^{\prime} \mathrm{S}, 36^{\circ} 20^{\prime} \mathrm{E}\right)$ of central Tanzania. The study area was stratified into low, intermediate and high altitudes. Wangi and Mwanawota (highland), Kibakwe and Kidenge (intermediate) and Chogola and Makose (lowland) were selected for the study. In each stratum, the selection of the villages was also based on the presence or absence of health facilities. Health facilities were available at Chogola, Kibakwe and Mwanawota. There were no health facilities at Makose, Kidenge and Wangi. Within each stratum, the villages were about $11 \mathrm{~km}$ apart. Coordinates were taken at the central point for each of the selected village using Global Positioning System. 


\section{Malariometric survey}

Malariometric surveys were carried out to cover approximately 200 schoolchildren in each village. Thick and thin blood smears were collected from each individual from a finger prick. The blood smears were stained with $10 \%$ Giemsa and examined under microscope in order to identify and quantify any malaria parasite species present.

Enumeration of the asexual malaria parasites was made against 200 leukocytes. A slide was considered negative if no parasite was seen after scanning 200 microscope fields under oil immersion with $\mathrm{x} 100$ objective. When gametocytes were present, they were enumerated against 500 leukocytes. Assuming an average of 8000 leukocytes per microlitre of blood, the number of parasite/ $\mu 1$ was estimated by multiplying by a factor of 40 for asexual forms. In addition, a fingerprick blood from a representative sample of 50 pupils from each village was taken into heparinised capillary tubes for packed cell volume (PCV) determination (Hughes-Jones, 1975). Each child screened for malaria parasite was asked whether he/she slept under a mosquito net during the previous night.

\section{Data analysis}

All malariometric and entomological data were entered into Excel and verified in database and analysed using version 8 of the STATA software package (Stata Corp, College Station, Texas).

\section{Results}

A total of 1119 schoolchildren (age $=5.9-12.3$ years) were clinically and parasitologically examined for malaria in six villages. The villages were situated between latitude 975 and $1859 \mathrm{~m}$ (Table 1). Of the total schoolchildren screened for malaria parasites Plasmodium falciparum and P. malariae accounted for $92.8 \%$ and $1.4 \%$ of all malaria parasite species, respectively. Mixed infections of $P$. falciparum $+P$. malariae $(4.1 \%)$ and $P$. falciparum + P. ovale $(1.4 \%)$ and $P$. falciparum $+P$. malariae $+P$. ovale $(0.3 \%)$ were also observed.

The overall mean malaria parasite rate was $25.8 \%$ (289/1119). Parasite rate was significantly lower in Chogola (with health facility) than in Makose (without health facility) $(P<0.001)$ in the lowlands. At

Table 1: Village locations and altitudes and availability of health care facility in Mpwapwa

\begin{tabular}{lcccc}
\hline Village & Longitude $^{\circ} \mathrm{S}$ & Latitudes $^{\circ} \mathrm{E}$ & Altitude $(\mathrm{m})$ & Health facility $^{\circ}$ \\
\hline Chogola & $06^{\circ} 55^{\prime} .070$ & $36^{\circ} 19^{\prime} .196$ & 975 & Dispensary \\
Makose & $06^{\circ} 54^{\prime} .503$ & $36^{\circ} 21^{\prime} .458$ & 990 & Absent \\
Kibakwe & $06^{\circ} 42^{\prime} .945$ & $36^{\circ} 22^{\prime} .564$ & 1136 & Health Centre \\
Kidenge & $06^{\circ} 45^{\prime} .759$ & $36^{\circ} 28^{\prime} .102$ & 1219 & Absent \\
Wangi & $06^{\circ} 44^{\prime} .523$ & $36^{\circ} 16^{\prime} .410$ & 1798 & Absent \\
Mwanawota & $06^{\circ} 40^{\prime} .219$ & $36^{\circ} 17^{\prime} .635$ & 1859 & Dispensary \\
\hline
\end{tabular}

\section{Entomological survey}

Mosquito collections were made using pyrethrum spray catch technique. In each village mosquitoes were collected from 10 houses. One room in each selected house was sprayed with pyrethrum during the morning hours, and after 10 minutes, the mosquitoes knocked down on the spread white cotton sheets were picked up and preserved in petri dishes lined with moist cotton wool and filter papers. All mosquitoes were morphologically identified (Gillies \& De Meillon, 1987), sorted according to site of collection, house and species. Female An. gambiae were dissected to determine parity by observing the degree of coiling of ovarian tracheoles (Detinova, 1962). Salivary glands of parous mosquitoes were examined for malaria parasites using standard dissection techniques (WHO, 1975). intermediate altitudes, parasite rate in Kibakwe, (with a health facility), was significantly lower than in Kidenge (without health facility) $(P<0.001)$. Similarly, in the highlands, the parasite rate in Mwanawota (with health facility) was significantly lower than in Wangi (without health facility) $(P<0.001)$. Communities living in areas with health care facilities were less at risk of acquiring malaria infection by $33.4 \%$ as compared with those living in areas without health facilities. Malaria prevalence in each of the three strata was 35.8\% (119/332), 38.8\% (150/387) and 5\% (20/ 400) for the low, intermediate and high altitude areas, respectively. 
Table 2: The number of schoolchildren, mean age, sex ratio, parasite rate, GMPD and spleen rate

\begin{tabular}{lcccccc}
\hline & Makose & Chogola & Kibakwe & Kidenge & Wangi & Mwanawota \\
\hline Number screened & 200 & 132 & 200 & 187 & 200 & 200 \\
Mean Age (years) & 5.9 & 8.5 & 9.6 & 11 & 12.3 & 11.6 \\
Sex ratio (M:F) & $0.92: 1$ & $0.59: 1$ & $0.98: 1$ & $0.94: 1$ & $1.32: 1$ & $0.80: 1$ \\
Parasite rate (\%) & 53.8 & 23.5 & 26.5 & 51.9 & 8.5 & 1.5 \\
GMPD/ul & 1448 & 364 & 299 & 214 & 276 & 880 \\
Spleen rate (\%) & 40.2 & 22.0 & 18.0 & 36.8 & 0 & 0 \\
\hline
\end{tabular}

The geometric mean parasite densities (GMPD) for P. falciparum, P. malariae and P. ovale were $361(\mathrm{~N}=286)$, $86(\mathrm{~N}=14)$, and $70(\mathrm{~N}=5)$ per microlitre of blood, respectively. The GMPDs were higher in Makose and Mwanawota villages and lower in Kibakwe and Kidenge villages (Table 2). The GMPD rates for $P$. falciparum varied significantly between villages with or without health facilities within similar altitudes.

There was no direct association between altitude and parasite density in this district. However, the higher GMPD in Mwanawota was observed from a very small sample of infected individuals. Higher spleen rates were observed in Makose and Kidenge, villages (Figure 1). The overall gametocyte parasite density for the district was $145.3 / \mu \mathrm{l}$ of blood. Of the total individuals with gametocytes, $0.3 \%$ was from villages with health facilities whereas $99.7 \%$ were from villages without health facilities.

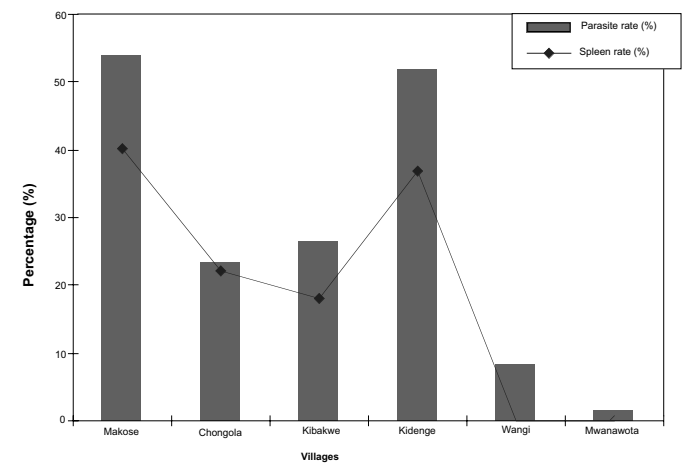

Figure 1: Parasite and spleen rates among school children in Mpwapwa

On average the district mean packed cell volume (PCV) among school children was 38.5\%. The mean PCV was higher in villages in the highlands than lowlands (Figure 2). PCV was high in villages with health facilities, although this was not statistically difference $(\mathrm{P}>0.05)$.
The average spleen rate in the district was $18.1 \%$. The spleen rates were significantly lower in villages with health facilities than those without health facilities within similar altitudes $(P<0.001)$. In both low and intermediate altitudes people living in villages with health facilities were at lower risk of having an enlarged spleen by $39.6 \%$ (95\%CI: $28.4-55.4 \%$ ) when compared to those living in areas without health facilities.

Anopheles gambiae sensu lato was the only malaria mosquito collected in the study area. An. gambiae s.l. was found in all villages, both at low and higher altitudes. On average 1.5 An. gambiae s.l. per room was found in the study villages. Higher sporozoite rates were found in Wangi, Kibakwe and Makose (Table 3).

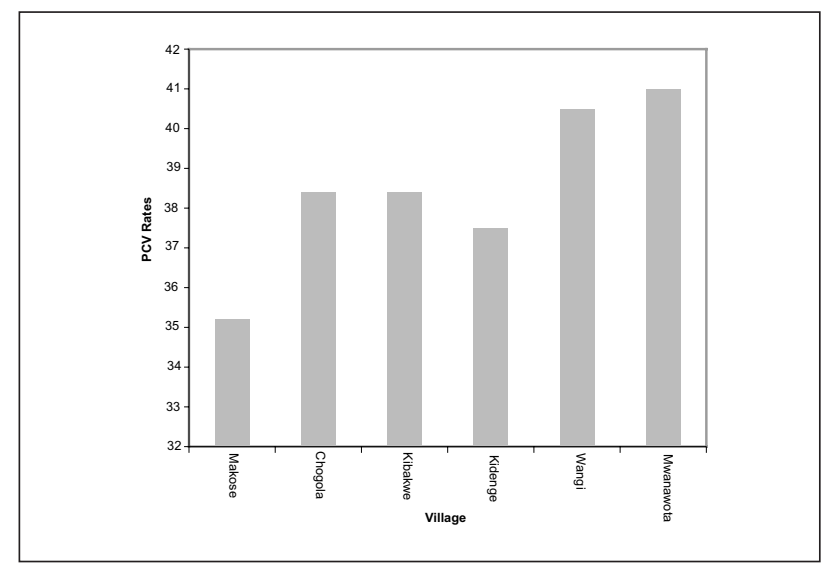

Figure 2: Packed cell volume rates in Mpwapwa

On average $2.1 \%$ of the schoolchildren were using mosquito nets for protection against malaria. Only $2.7 \%$ (5/187) and 9.5\% (19/200) of the schoolchildren were sleeping under mosquito nets in Kidenge and Kibakwe, respectively. Significantly, a larger proportion of children were sleeping under mosquito nets in Kibakwe than in Kidenge $\left(P=0.005, \chi^{2}=7.74\right)$. All children in Wangi, Mwanawota, Chogola and Makose were not sleeping under a mosquito net. 
Table 3: Number, parity and infectivity rates of An. gambiae s.l. collected in Mpwapwa district

\begin{tabular}{lccc}
\hline Village & Number & Parity $\%$ & Sporozoite $\%$ \\
\hline Wangi & 12 & 90.1 & 8.3 \\
Mwanawota & 6 & 33.3 & 0 \\
Kidenge & 21 & 42.9 & 0 \\
Kibakwe & 21 & 76.9 & 10.5 \\
Chogola & 7 & 80 & 0 \\
Makose & 19 & 50 & 4.8 \\
Total & 86 & 68.9 & 5.3 \\
\hline
\end{tabular}

\section{Discussion}

The district mean malaria parasite rate of $25.8 \%$ and spleen rate of $18.1 \%$ in school children indicate that malaria in the district is mesoendemic. A previous survey made in Hombolo, in the nearby district of Dodoma, revealed parasite rate of $31.4 \%$ among children 6-10 years (Clyde, 1967).

In our study, a variation of parasite rate was observed between villages within similar altitudes. Like in other studies, the malaria parasite rates were high at lower altitudes of Makose and Chogola than at higher altitudes of Wangi and Mwanawota. Previous studies in the district have shown similar results (Goosen, 1973).

The endemicity of the disease varied according to altitudes and the presence or absence of a health care facility. Higher proportions of the population were infected with malaria parasites in lower altitudes and villages without health facilities than the vice-versa. Interestingly, in this study malaria parasitaemia, though at a lower rate, could be detected in individuals living over $1800 \mathrm{~m}$ above sea level. Similar observations have been reported recently in the Usambara Mountains (Bødker at al., 1997) and Ngorongoro (Mboera et al., 2005), in north-east and northern Tanzania, respectively.

The relationship between malaria prevalence and altitude may be related to availability of optimal conditions for the development of malaria parasites in the mosquito vectors. It has been established that the developmental rates increase from zero at a low temperature threshold, reach a maximum at an optimal temperature and decrease rapidly to zero at an upper, lethal temperature (Lactin et al., 1995).

In Africa, the efficient malaria mosquitoes are lowland sun-loving savannah species, and malaria is negatively associated with altitude. However, in northeastern Tanzania, deforestation has led to the spread of malaria upward into the hilltop villages $(c .1000 \mathrm{~m})$ of the Usambara Mountains (Matola et al., 1987). This was attributed partly to the creation of sunlit breeding sites, but also to the great increase in temperature (from $12.8-15.6^{\circ} \mathrm{C}$ to $17.7-20.8^{\circ} \mathrm{C}$ ) that accompanied forest clearing.

Mixed malaria parasite infections were observed in Mpwapwa district. Infections due to two or more species of malaria parasites in other places are common (Gilles, 1993), but they are often overlooked. There is a tendency for one species of the parasite to predominate over the other. The most common types of mixed infections in tropical Africa are P. falciparum and $P$. malariae, although $P$. falciparum and $P$. ovale are also frequent. On rare occasions all three species can be found in one blood film as was observed in Mpwapwa.

The low PCV levels observed in this study correlated with the parasite density. It should be noted however, that the higher parasite density observed in Wangi is due to the small sample size. The few individuals observed carrying malaria parasites were heavily infected. The relatively higher packed cell volume observed in the district could be attributed to type and quantity of food available and/ or malaria endemicity. There seems to be a slight relationship between higher PCV levels and the presence of health facilities, as the levels were higher in villages with health care facilities. The possibility for early diagnosis and prompt treatment for those living close to health care facility is most likely to contribute to the low malaria parasite density and hence high packed cell volumes.

The overall proportion of the population in the study areas using mosquito nets was lower than expected. In the nearby Iringa district, mosquito net coverage was found to be $16.1 \%$ (Mboera et al., 2006). Interestingly, the use of mosquito nets was high in larger settlement such as Kibakwe than in typical small rural villages. 
The higher proportion of net use that was observed at Kibakwe, a village with health facility than in other villages, is most probably due to the presence of large number of nuisance Culex mosquitoes (data not shown) and health education that is likely to be provided by the health facility.

In conclusion, malaria prevalence among communities in Mpwapwa district varies with altitude and that the presence health care facility plays a significant role in the low malaria parasitaemia levels among the population in the vicinity. Similar observations have been made in a nearby district of Iringa (Mboera et al., 2006). These results therefore, provide more evidence that individuals with easy access to health care services are likely to be less at risk of carrying malaria infection than those living far away. There is need therefore to strengthen health care provision for early diagnosis and treatment of cases and hence lower parasite infection among the population.

\section{Acknowledgements}

We wish to acknowledge the District Commissioner, District Executive Officer, District Medical Officer and District Education Officer of Mpwapwa for facilitating this study. We also extend our thanks to the teachers of the schools involved in the study and to the village leaders. This study received financial assistance from the Italian Co-operation and the National Institute for Medical Research.

\section{References}

Bødker, R. (2000) Variation in the malaria risk in the Usambara Mountains, Tanzania. PhD thesis. University of Copenhagen, Denmark.

Billingsley, P.F., Charlwood, J.D. \& Knols, B.G.J. (2006) Rapid assessment of malaria risk using entomological techniques: taking an epidemiological snapshot. In: Environmental Change and Malaria Risk (eds: W. Takken, P. Martens, R.J. Bogers). Wageningen UR Frontis Series Vol 9. Springer. Pp 51-68.

Charlwood, J.D., Kihonda, J., Sama, S., Billingsley, P.F., Hadji, H., Verhave, J.P. (1995) The rise and fall of Anopheles arabiensis (Diptera: Culicidae) in a Tanzanian village. Bulletin of Entomological Research 85, 37-44.

Clyde, D.F (1967) Malaria in Tanzania. London, Oxford University Press.
Detinova, T.S. (1962) Age-grouping methods in Diptera of medical importance. W.H.O. Monograph 47.

Gilles, H.M. (1993) The malaria parasites. In: BruceChwatt's Essential Malariology, $3^{\text {rd }}$ edn, H.M. Gilles \& D.A. Warrell, eds.) Arnold, London. Pp13-31.

Gillies, M.T. \& De Meillon, B. (1968) The Anophelinae of Africa south of the Sahara (Ethiopian zoogeographical region) $\left(2^{\text {nd }} E d\right.$.) Johannesburg: The South African Institute for Medical Research.

Goosen, Th. J. 1973, Parasitological and immunoserological studies on the epidemiology of malaria in Dodoma Region. Annual Report of the East African Institute of Malaria and Vector-borne Diseases pp. 41-49.

Hughes-Jones, NC: (1975) Lecture Notes on Haematology. $2^{\text {nd }}$ Edition. Blackwell Scientific Publication, pp. 154.

Karanja, D.M., Alaii, J., Abok, K., Achigo, N.I., Githeko, A.K., Seroney, I., Vulule, J.M., Odada, P. \& Oloo, J.A. (1999) Knowledge and attitude to malaria and acceptability of permethrin impregnated sisal curtains. East African Medical Journal 76: 42-46

Koenraadt, C.J.M. (2003) Mosquitoes, men and malaria in Kenya. A study on ecological factors affecting malaria risk. $\mathrm{PhD}$ Thesis, Wageningen University Dissertation No. 3482.

Lindsay, S.W., Ansell, J., Selman, C., Cox, V., Hamilton, K. \& Walraven, G. (2000) Effect of pregnancy on exposure to malaria mosquitoes. The Lancet 355, 1972.

Marsh K, Forster D, Waruiru C, Mwangi I, Winstanley M, Marsh V, Newton C, Winstanley P, Warn P, Peshu N, Pasvol G, Snow R (1995) Indicators of life-threatening malaria in African children. New England Journal of Medicine 332, 1399-1404.

Matola, Y.G., White, G.B. \& Magayuka, S.A. (1987) The changed pattern of malaria endemicity and transmission at Amani in the eastern Usambara Mountains, north-eastern Tanzania. Journal of Tropical Medicine and Hygiene $\mathbf{9 0 ,}$ 127-134.

Mboera, L.E.G., Malima, R.C., Mangesho, P.E., Senkoro, K.P. \& Mwingira, V. (2005) Malaria among the pastoral communities of the Ngorongoro Crater area, northern Tanzania. Tanzania Health Research Bulletin 7, 79-87. 
Mboera, L.E.G., Kamugisha, M.L., Rumisha, S.F., Kisinza, W.N., Senkoro, K.P. \& Kitua, A.Y. (2006) Variation in malaria prevalence with altitude in the presence or absence of health facilities in Iringa District, Tanzania. Malaria Journal (submitted)

Mboera, L.E.G. (2000) Fifty Years of Health Research in Tanzania. An annotated bibliography. 373 pp. DUP (1996) Ltd.

Mboera, L.E.G. \& Kitua, A.Y. (2001) Malaria epidemics in Tanzania. African Journal of Health Sciences 8, 14-18.
Odongo-Aginya, E., Ssegwanyi, G., Kategere, P. \& Vuzi, P.C. (2005) Relationship between malaria infection intensity and rainfall pattern in Entebbe peninsula, Uganda. African Health Sciences 5, 238-245.

Verhoef, H., West, C.E., Veenemans, J., Beguin, Y. \& Kok, F.J. (2002) Stunting may determine the severity of malaria-associated anemia in African children. Pediatrics 110, e48.

WHO (1975) Manual on Practical Entomology in Malaria: Part II - Methods and Techniques. WHO Offset Publications No. 13, Geneva. 